Journal of Current and Advance Medical Research

July 2019, Vol. 6, No. 2, pp. 77-82

http://www.banglajol.info/index.php/JCAMR

ISSN (Print) 2313-447X

ISSN (Online) 2413-323X

NLM Catalog ID 101673828

DOI: https://doi.org/10.3329/jcamr.v6i2.42698

ORIGINAL ARTICLE

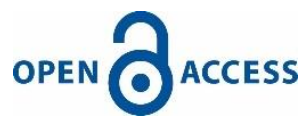

\title{
Comparison of Propranolol and Amitriptyline as Monotherapy for Migraine Prophylaxis
}

\author{
Mohammad Ariful Islam ${ }^{1}$, Dahlia Sultana ${ }^{2}$, Mohammad Selim Shahi ${ }^{3}$, Mohammad Sayeed Hassan ${ }^{4}$ \\ ${ }^{1}$ Assistant Professor, Department of Neurology, National Institute of Neurosciences \& Hospital, Dhaka, Bangladesh; ${ }^{2}$ Assistant \\ Professor, Department of Endocrinology, Sir Salimullah Medical College, Dhaka, Bangladesh; ${ }^{3}$ Associate Professor, Department of \\ Neurology, National Institute of Neurosciences \& Hospital, Dhaka, Bangladesh; ${ }^{4}$ Assistant Professor, Department of Neurology, \\ National Institute of Neurosciences \& Hospital, Dhaka, Bangladesh
}

[Received on: 12 February 2019; Reviewed on: 1 March 2019; Accepted on: 26 April 2019; Published on: 1 July 2019]

\section{Abstract}

Background: Several drugs are used individually for migraine prophylaxis. Objective: The purpose of the present study was to compare the propranolol and amitriptyline as monotherapy for the prophylaxis of migraine. Methodology: This randomized control trial was conducted in headache clinic at Banghabandhu Sheikh Medical University (BSMMU), Dhaka, Bangladesh from July 2012 to June 2014 for a period of two (02) years. Migraine patients with or without aura of 16 to 50 years of age, patients not on any prophylactic medication were included for this study. Patients meeting all the criteria was randomized group A who were treated with Amitriptyline and group B who were treated with propranolol. Patients was followed for a three months period during which they was instructed to maintain a headache diary. The primary outcome evaluated was the proportion of patients in each group that achieved a 50\% reduction in the number of days with headache. Result: A total 80 adult patients were selected. During $1^{\text {st }}$ visit among the patients duration of pain 1 to 4 hours (2.5.0\%), 5 to 8 hours (13.3\%) 9 to 12 hours (35.0\%) and above 13 hours $(22.5 \%)$ in group A were recorded; however, in group B, duration of pain 1 to 4 hours 1(2.5), 5-8 hours 16(13.3\%), 9-12 hours 19(47.5) and above 13 hours 4(10.0) (p>0.05). In group A, no adverse effect was found $26(65.0 \%)$, drowsiness $6(15.0 \%)$, dryness of mouth 6(15.0\%), constipation $2(5.0 \%)$, fatigue and bradycardia were not found. In group B, no adverse effect was found 29(72.5\%), drowsiness, dryness of mouth and constipation were not found, fatigue and bradycardia were $7(17.5 \%)$ and 4(10.0\%). Conclusion: In conclusion number of attack and headache before treatment gradually decrease in subsequent follow up in both groups. [Journal of Current and Advance Medical Research 2019;6(2):77-82]

Keywords: Propranolol; Amitriptyline; monotherapy; Migraine Prophylaxis

Correspondence: Dr. Mohammad Ariful Islam, Assistant Professor, Neurology, National Institute of Neurosciences \& Hospital, Dhaka, Bangladesh; Email: drariful22@gmail.com; Cell no.: +8801715016462

Cite this article as: Islam MA, Sultana D, Shahi MS, Hassan MS. Comparison of Propranolol and Amitriptyline as monotherapy for Migraine Prophylaxis. J Curr Adv Med Res 2019;6(2):77-82

Funding: This study has been performed without any funding from outside else.

Conflict of Interest: There was no conflict of interest to any of the authors.

Contributions to authors: Islam MA, Sultana D, have contributed in protocol preparation, data collection, data analysis upto the report writing; Shahi MS, Hassan MS have prepared \& have revised the manuscript.

Copyright: (O2019. Islam et al. Published by Journal of Current and Advance Medical Research. This article is published under the Creative Commons CC BY-NC License (https://creativecommons.org/licenses/by-nc/4.0/). This license permits use, distribution and reproduction in any medium, provided the original work is properly cited, and is not used for commercial purposes. 


\section{Introduction}

Migraine headache are usually characterized by pain on one or both sides of the head ${ }^{1}$. Migraine headaches are often accompanied by photophobia, phonophobia and vomiting. It is a common condition which is annually affecting $12.0 \%$ of the United states population, including $18 \%$ of women, $6.0 \%$ of men and $4.0 \%$ of children ${ }^{2}$. Different elements need to be considered in migraine management. These include avoidance of trigger factors, lifestyle modifications, nonpharmacological therapies and medications ${ }^{3}$.

Pharmacological treatment is traditionally divided into acute or symptomatic treatment, and preventive treatment or prophylaxis ${ }^{4}$. Many migraine patients can be treated using only acute treatment that is, prescribing medications that are used only during headache attacks to abort an ongoing attack or to stop its progression to severe pain and associated symptoms. Patients with severe and/or frequent migraines require long-term preventive therapy ${ }^{5}$. A variety of drugs from diverse pharmacological classes are in use for migraine prevention. Adrenergic receptor blockers like propranolol, tricyclic antidepressants like amitriptyline, anticonvulsants like topiramate and valproate and serotonergic drugs like methysergide are most commonly administered for this purpose ${ }^{6-7}$. Currently, topiramate was tested prospectively and proved effective ${ }^{8}$ based on the prior success of certain anticonvulsants, despite acknowledged differences between migraine and epilepsy. Betaadrenergic blockers, such as propranolol, are among the most prescribed drugs for migraine prophylaxis $^{9-10}$.

There is clear evidence that propranolol is more effective than placebo in the treatment of migraine ${ }^{9}$. The usual propranolol doses for migraine prevention in clinical trials have ranged from 80 to $160 \mathrm{mg}$ a day ${ }^{9-12}$. Adverse events most commonly reported with beta-blockers are fatigue, depression, nausea, dizziness, and insomnia ${ }^{11}$. These symptoms are fairly well tolerated and are seldom the cause of premature withdrawal. Antidepressants, especially tricyclic agents such as amitriptyline and nortriptyline, have also been a mainstay in the prophylatic therapy of migraine ${ }^{14}$. Amitriptyline is a mixed serotonergic and noradrenergic reuptake inhibitor with well-established efficacy in chronic pain relief and migraine prophylaxis ${ }^{15-16}$. It is useful for the treatment of patients with migraine and comorbid depression ${ }^{17}$. Common side effects of amitriptyline include dry mouth, constipation, and sedation. They may also cause slowing of atrioventricular conduction and orthostatic hypotension.

Most studies have evaluated the efficacy of such drugs alone; however, there are some studies with propranolol $^{18,19}$ and tricyclic agents ${ }^{20}$ in association with other drugs. The clinical experience with combination therapy for migraine seems to be a rational approach when monotherapy fails and when migraine is refractory ${ }^{21}$. This clinical trial study was carried out to see safety and efficacy of propranolol and amitriptyline as monotherapy in migraine prophylaxis.

\section{Methodology}

Study Settings and Population: This study was designed as single centre, parallel, randomized control trial. This study was conducted in headache clinic at Banghabandhu Sheikh Medical University (BSMMU), Dhaka, Bangladesh from July 2012 to June 2014 for a period of two (02) years. Migraine patients with or without aura of 16 to 50 years of age, patients not on any prophylactic medication and patients willing to take part in the study were included for this study. Age less than 16 years or more than 50 years, patients with chronic migraine, complicated migraine, ophthalmoplegic migraine, basilar migraine, catamenial migraine, patients on prophylactic medication, pregnant women, lactating mother, patients having history of bronchial asthma, cardiac arrhythmia, ischemic heart disease, bladder outlet obstruction or any known hypersensitivity to these drugs, patients with any serious co morbid condition such as uncontrolled hypertension, heart failure, hepatic or renal impairment, diabetes mellitus were excluded from this study. Informed written consent was taken from all patients. Migraine was diagnosed according to the criteria of the Headache Classification Committee of the International Headache Society ${ }^{22}$. Detailed history, general examination, neurological examination including fundoscopy and relevant systemic examination was done. Before the commencement of the study, the protocol for the following study was approved by ethical authority.

Randomization and Blinding: Patients meeting all the criteria was randomized for two (02) treatment groups designated as the group A who were treated with amitriptyline and the group B who were treated with propranolol. Blinding was not performed.

Intervention: The doses of propranolol was $20 \mathrm{mg}$ $\mathrm{BD}$ for the first two weeks, $20 \mathrm{mg}$ TDS for the next 
two weeks and finally $40 \mathrm{mg} \mathrm{BD}$ for the consecutive 8 weeks. The doses of amitriptyline was $10 \mathrm{mg}$ in the first two weeks and $25 \mathrm{mg}$ during second two weeks once at bedtime and $50 \mathrm{mg}$ at bed time in the next 8 weeks. The doses of each of these drugs was the same when given alone or in combination.

Follow up and Outcome Measures: Patients was followed for a three months period during which they was instructed to maintain a headache diary with the following information: presence of headache and intensity of headache by Visual Analogue Pain Scale. This was also include the need for analgesic for headache. Patients was asked to return on days 30,60 and 90. The primary outcome evaluated was the proportion of patients in each group that achieved a $50 \%$ reduction in the number of days with headache. Secondary outcomes was reduction of visual analogue pain scale score, the number of days with headache per month, frequency of side effects, and the proportion of patients abandoning the study before the end of medication. The causes of noncompliance and side effects was individually registered.

Statistical Analysis: After collection all the data were checked and edited. Then data were entered into the computer with the help of software SPSS for windows programmed version 16.0. After frequency run, data were cleaned and frequencies were checked. An analysis plan was developed keeping in view with the objectives of the study. Cross tabulation was prepared and a comparison had been made between, Data was presented as means (SD) and analyzed with 2-tailed $\boldsymbol{t}$ tests when normally distributed. Every data was kept confidential.

\section{Results}

This study was carried out to see the efficacy of propranolol and amitriptyline as monotherapy for migraine prophylaxis. A total 80 adult patients were selected according to selection criteria. The patients were categorized in to 2 groups. Group A received Amitribtyline, Group-B received Propanolol. They were interviewed with a specific pre-designed and pre-tested questionnaire and some information were gathered by document review. Collected data were cleaned, edited and analyzed with the help of software SPSS. The analyzed data have been presented in this chapter through tables and appropriate graphs.

\section{Table 1: Distribution of age among the patient}

\begin{tabular}{|l|c|c|}
\hline Age group & Group A & Group B \\
\hline 16 to 25 Years & $24(60.0 \%)$ & $20(50.0 \%)$ \\
\hline 26 to 35 Years & $14(35.0 \%)$ & $15(37.5 \%)$ \\
\hline$\geq 36$ Years & $2(5.0 \%)$ & $5(12.5 \%)$ \\
\hline Total & $\mathbf{4 0}(\mathbf{1 0 0 . 0 \%})$ & $\mathbf{4 0}(\mathbf{1 0 0 . 0 \%})$ \\
\hline
\end{tabular}

$\mathrm{P}$ value $=0.208$

Table 1 shows that distribution of age among the patient. In group A, 16-25 age group were 24 (60.0\%), 26-35 age group were 14 (35.0\%), 36 and above age group were $2(5.0 \%)$. In group B, 16-25 age group were $20(50.0 \%), 26-35$ age group were $15(37.5 \%), 36$ and above age group were 5 $(12.5 \%)$. The association was not statistically significant.

Table 2: Duration of pain found in First follow up among the patients

\begin{tabular}{|l|c|c|c|c|}
\hline \multirow{2}{*}{ Duration } & \multicolumn{2}{|c|}{ Group A } & \multicolumn{2}{c|}{ Group B } \\
\cline { 2 - 5 } & $\mathbf{1}^{\text {st }} \mathbf{F U}$ & Final FU & $\mathbf{1}^{\text {st }} \mathbf{F U}$ & Final FU \\
\hline 1-4hours & $1(2.5 \%)$ & $24(60.0 \%)$ & $1(2.5 \%)$ & $20(50.0 \%)$ \\
\hline 5-8 hours & $16(13.3 \%)$ & $14(35.0 \%)$ & $16(13.3 \%)$ & $15(37.5 \%)$ \\
\hline 9-12hours & $14(35.0 \%)$ & $2(5.0 \%)$ & $19(47.5 \%)$ & $5(12.5 \%)$ \\
\hline$>13$ hours & $9(22.5 \%)$ & $0(0.0 \%)$ & $4(10.0 \%)$ & $0(0.0 \%)$ \\
\hline Total & $\mathbf{4 0}(\mathbf{1 0 0 . 0 \%})$ & $\mathbf{4 0}(\mathbf{1 0 0 . 0 \%})$ & $\mathbf{4 0}(\mathbf{1 0 0 . 0 \%})$ & $\mathbf{4 0}(\mathbf{1 0 0 . 0 \%})$ \\
\hline
\end{tabular}

Gr-A Amitriptyline; Gr-B Combination

Table 2 shows that duration of pain found in during $1^{\text {st }}$ visit among the patients. In group A, duration of pain 1 to 4 hours $1(2.5 .0 \%), 5$ to 8 hours $16(13.3 \%) 9$ to 12 hours $14(35.0 \%)$. Above 13 hours $9(22.5 \%)$ In group B, duration of pain 1 to 4 hours $1(2.5), 5$ to 8 hours $16(13.3 \%), 9$ to 12 hours 19(47.5) and above 13 hours 4(10.0). The difference were not statistically significant. The duration of pain in final follow up was recorded among the patients. In group $\mathrm{A}$, duration of pain 1 
to 4 hours 24 (60.0\%), 5 to 8 hours 14 (35.0\%), 9 to 12 hours $2(5.0 \%)$. In group B, duration of pain 1 to 4 hours $20(50.0 \%), 5$ to 8 hours $15(37.5 \%), 9$ to 12 hours $12(30.0 \%)$. The different was not statistically significant.

Table 3: Distribution of patients by side effects of drugs

\begin{tabular}{|l|c|c|}
\hline Adverse effects & Group A & Group B \\
\hline No AD & $26(65.0 \%)$ & $29(72.5 \%)$ \\
\hline Drowsiness & $6(15.0 \%)$ & $0(0.0 \%)$ \\
\hline Dry mouth & $6(15.0 \%)$ & $0(0.0 \%)$ \\
\hline Constipation & $2(5.0 \%)$ & $0(0.0 \%)$ \\
\hline Fatigue & $0(0.0 \%)$ & $7(17.5 \%)$ \\
\hline Bradycardia & $0(0.0 \%)$ & $4(10.0 \%)$ \\
\hline Total & $\mathbf{4 0}(\mathbf{1 0 0 . 0 \%})$ & $\mathbf{4 0}(\mathbf{1 0 0 . 0 \%})$ \\
\hline
\end{tabular}

$\mathrm{P}$ value $=0.000 ; \mathrm{AD}=$ adverse effect

In group A, no adverse effect was found 26 (65.0\%), drowsiness 6 (15.0\%), dryness of mouth 6 (15.0\%), constipation 2 (5.0\%), fatigue and bradycardia were not found. In group B, no adverse effect was found 29 (72.5\%), drowsiness, dryness of mouth and constipation were not found, fatigue and bradycardia were $7(17.5 \%)$ and $4(10.0 \%)$ (Table 3).

Table 4: Number of attack and headache before treatment and subsequent follow up

\begin{tabular}{|l|c|c|c|}
\hline Number of & Group A & Group B & P value \\
\hline $\begin{array}{l}\text { Attack } \\
\text { Before } \\
\text { Treatment }\end{array}$ & $5.825 \pm 2.18$ & $6.575 \pm 1.87$ & 0.085 \\
\hline $\begin{array}{l}\text { Attach } \\
\text { During 1st } \\
\text { Follow Up }\end{array}$ & $3.625 \pm 1.89$ & $4.575 \pm 1.29$ & 0.013 \\
\hline $\begin{array}{l}\text { Attach } \\
\text { During 2nd } \\
\text { Follow Up }\end{array}$ & $2.475 \pm 1.67$ & $3.5 \pm 1.13$ & 0.002 \\
\hline $\begin{array}{l}\text { Attach } \\
\text { During 3rd } \\
\text { Follow Up }\end{array}$ & $1.675 \pm 1.09$ & $2.375 \pm 1.39$ & 0.0001 \\
\hline $\begin{array}{l}\text { Headache } \\
\text { Before } \\
\text { Treatment }\end{array}$ & $7.625 \pm 2.50$ & $8.325 \pm 2.03$ & 0.094 \\
\hline $\begin{array}{l}\text { Headache } \\
\text { During 1st } \\
\text { Follow Up }\end{array}$ & $4.675 \pm 2.23$ & $5.775 \pm 2.09$ & 0.037 \\
\hline $\begin{array}{l}\text { Headache } \\
\text { During 2nd } \\
\text { Follow Up }\end{array}$ & $2.875 \pm 2.11$ & $4.275 \pm 1.35$ & 0.001 \\
\hline $\begin{array}{l}\text { Headache } \\
\text { During 3 } \\
\text { Follow Up }\end{array}$ & $2.35 \pm 1.64$ & $3.075 \pm 1.65$ & 0.005 \\
\hline
\end{tabular}

Number of attack and headache before treatment and subsequent follow up with medication it was found that number of attach and headache gradually decrease. The differences are statistically significantly (Table 4).

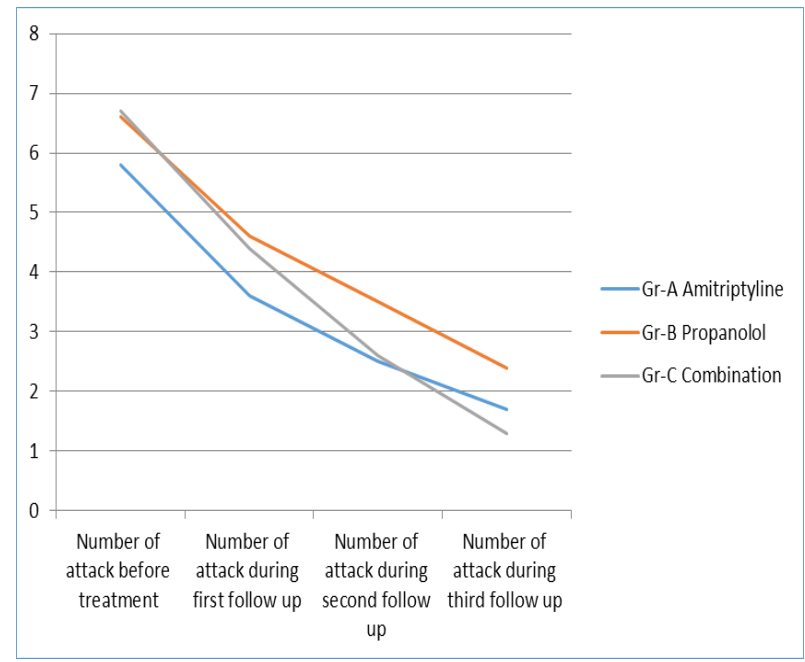

Figure I: Number of Attack before treatment and final, second and third follow up

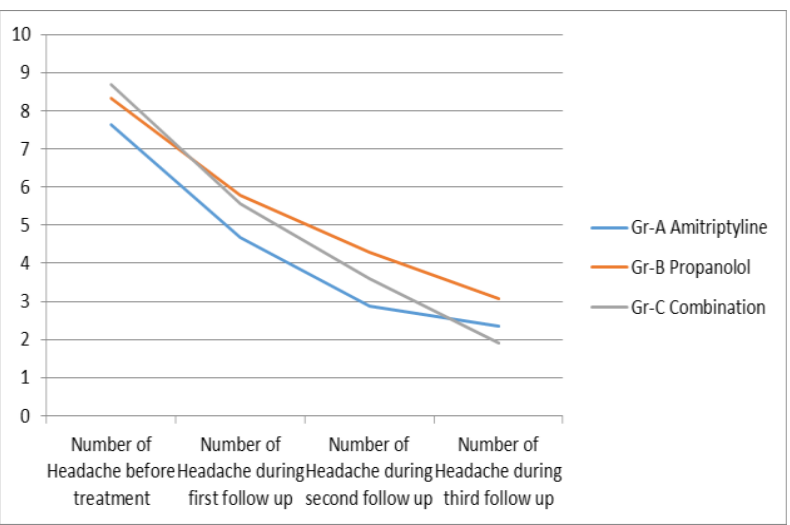

Figure II: Number of Headache before treatment and final, second and third follow up

\section{Discussion}

Propranolol and amitriptyline are two commonly used drugs for migraine prophylaxis ${ }^{3}$. Both drugs are cheap, available and effective and have been in use for a long time in prevention of migraine. In clinical practice these drugs can be used alone or in combination.

The treatment of migraine involves both acute and preventive drugs and non- pharmacological strategies. Preventive treatment is necessary when the migraine attacks are unacceptably frequent, prolonged, severe, unresponsive to acute medication or associated with hemiparesis or 
prolonged aura. It is therefore designed to reduce the frequency, duration and/or severity of the attacks. In addition, preventive treatment often makes migraine attacks more responsive to acute migraine therapies, reduces migraine associated disability, improves the patients' ability to function and decreases health care costs and use of healthcare resources ${ }^{13}$. This study is intended to compare the efficacy and safety of propranolol and amitriptyline in prevention of migraine attack when used alone or in combination.

In this present study a total of 120 patients were studied and were divided into three groups, total 120 adult patients were selected and according to selection criteria divided into three groups, Group A received Amitriptyline, Group B received Propanolol. In group A, 16 to 25 age group were $24(60.0 \%), 26$ to 35 age group were $14(35.0 \%), 36$ and above age group were $2(5.0 \%)$. In group B, 16 to 25 age group were $20(50.0 \%), 26$ to 35 age group were $15(37.5 \%), 36$ and above age group were $5(12.5 \%)$. The mean age of study population was $27.22 \pm 7.85$ and their minimum and maximum age were 16 years and 60 years respectively. Similar result was reported by Peterlin et $\mathrm{al}^{21}$ and mentioned that migraines usually develop in childhood, adolescence or early adulthood. Chowdhury ${ }^{13}$ documented that prevalence peak of migraine is at about age 40 and then prevalence declines progressively which is not headache intensity declined from 40 years to 74 years without change in headache frequency or headache duration which is consistent with the present study.

Duration of pain found during 1st visit among the patients in group A, duration of pain 1-4 hours 1 (2.5.0\%), 5-8 hours 16 (13.3\%), 9-12 hours 14 $(35.0 \%)$ and above 13 hours $9(22.5 \%)$. In group B, duration of pain 1-4 hours 1 (2.5), 5-8 hours 16 (13.3\%), 9-12 hours 19 (47.5) and above 13 hours 4 (10.0). In group C, duration of pain 1-4 hours $0(0.0)$, 5-8 hours 18 (15.0) 9-12 were 21 (52.5), above 13 hours pain duration were $1(2.5 \%)$. Duration of pain found in final follow up among the patients; in group A, duration of pain 1-4 hours $24(60.0 \%), 5-8$ hours $14(35.0 \%), 9-12$ hours $2(5.0 \%)$. In group B, duration of pain 1-4 hours 20 (50.0\%), 5-8 hours 15 (37.5\%), 9-12 hours $12(30.0 \%)$. In group C, duration of pain 1-4 hours 28 (70.0\%), 5-8 hours 12 (30.0\%), 9-12 hours were not found. There was no significant relationship between pain and migraine ( $\mathrm{p}$ $>0.05$ ). Similar resu;t has been reported by Bordini et $\mathrm{al}^{18}$.

Distribution of patients by side effects of drugs, in group A, no adverse effect was found $26(65.0 \%)$, drowsiness $6(15.0 \%)$, dryness of mouth $6(15.0 \%)$, constipation $2(5.0 \%)$, fatigue and bradycardia were not found. In group B, no adverse effect was found $29(72.5 \%)$, drowsiness, dryness of mouth and constipation were not found, fatigue and bradycardia were $7(17.5 \%)$ and $4(10.0 \%)$. In group C, no adverse effect was found $22(55.0 \%)$, drowsiness 8 (20.0\%), dryness of mouth $6(15.0 \%)$, constipation 2 $(5.0 \%)$, fatigue $2(5.0 \%)$ and bradycardia were not found. In conclusion side effects are no adverse effect throughout the period of study.

Number of attack and headache before treatment and subsequent follow up with medication it was found that number of attach and headache gradually decrease. The differences are statistically significantly.

Although optimum care had been tried by the researcher in every steps of this study, still some limitations existed: The study was conducted in a selected area. So the study population might not represent the whole the people. Time and budget constraints were also an important limitation of this study. In spite of maximum effort by the researcher due to time and resource limitation sample size was small; a larger sample size would have given a better result.

\section{Conclusion}

The study findings of this study shown that the efficacy of Propranolol and Amitriptyline in combination is more effective than monotherapy of Amitriptyline in migraine prophylaxis. The side effects are minimum than monotherapy. A large scale and multicenter study should be done to evaluate efficacy of Propranolol and Amitriptyline in combination is more effective than monotherapy of either drug in migraine prophylaxis.

\section{References}

1. Goadsby PJ, Raskin NH. Chapter 15. Headache. In: Fauci AS, Braunwald E, Kasper DL, Hauser SL, Longo DL, Jameson JL, et al., eds. Harrison's principles of internal medicine. 17th ed. New York: The McGraw-Hill Companies; 2008

2. Silberstein SD. Preventive migraine treatment. Neurol Clin. 2009;27(2):429-43

3. Solomon GD, Santanello N. Impact of migraine and migraine therapy on productivity and quality of life. Neurology. 2000;55(9 Suppl 2):S29-35

4. Lipton RB, Stewart WF, Diamond S, et al. Prevalence and burden of migraine in the United States: data from the American Migraine Study II. Headache 2001;41:646-657

5. Hannan MA et al, Study of epidemiological features of primary headache patients in a tertiary centre in Bangladesh. Bangladesh J Neuroscience 2007;23(1);11-22 
6. Habib M et al. Headache, study of 3350 cases. Bangladesh J Neuroscience. 2001;17(1):1-5

7. Silberstein SD. Practice parameter: evidence-based guidelines for migraine headache (an evidence-based review): report of the Quality Standards Subcommittee of the American Academy of Neurology. Neurology 2000;55:754-762

8. Brandes JL, Saper JR, Diamond M, et al. Topiramate for migraine prevention: a randomized controlled trial. JAMA 2004; 291:965-973

9. Linde K, Rossnagel K. Propranolol for migraine prophylaxis. Cochrane Database Syst Rev 2004:CD003225

10. Tvedskov JF, Thomsen LL, Thomsen LL, et al. The effect of propranolol on glyceryltrinitrate-induced headache and arterial response. Cephalalgia 2004;24:1076-1087

11. Pradalier A, Serratrice G, Collard M, et al. Long-acting propranolol in migraine prophylaxis: results of a double-blind, placebo-controlled study. Cephalalgia 1989;9:247-253

12. al-Qassab HK, Findley LJ. Comparison of propranolol LA $80 \mathrm{mg}$ and propranolol LA $160 \mathrm{mg}$ in migraine prophylaxis: a placebo controlled study. Cephalalgia 1993;13:128-131

13. Chowdhury MI, Study on propranolol vs sodium valproate in the prevention of migraine, Dept. of Neurology, BSMMU,2006

14. Punay NC, Couch JR. Antidepressants in the treatment of migraine headache. Curr Pain Headache Rep 2003;7:51-54
15. Ramadan NM. Prophylactic migraine therapy: mechanisms and evidence. Curr Pain Headache Rep 2004;8:91-5

16. Bigal ME, Krymchantowski AV, Rapoport AM. Prophylactic migraine therapy: emerging treatment options. Curr Pain Headache Rep 2004;8:178-84

17. Campo-Arias A. Antidepressants in migraine prophylaxis: an approximation. Rev Neurol 2004;38:864-8

18. Bordini CA, Arruda MA, Ciciarelli MC, Speciali JG. Propranolol vs flunarizine vs flunarizine plus propranolol in migraine without aura prophylaxis: a double-blind trial. Arq Neuropsiquiatr 1997;55:536-341

19. Kaniecki RG. A comparison of divalproex with propranolol and placebo for the prophylaxis of migraine without aura. Arch Neurol 1997;54:1141-1145

20. Keskinbora K, Aydinli I. A double-blind randomized controlled trial of topiramate and amitriptyline either alone or in combination for the prevention of migraine. Clin Neurol Neurosurg 2008;110:979-984

21. Peterlin BL, Calhoun AH, Siegel S, Mathew NT. Rational combination therapy in refractory migraine. Headache 2008;48:805-819

22. Headache Classification Committee of the International Headache Society, 2004 